\title{
Protective effect of silencing Stat 1 on high glucose-induced podocytes injury via Forkhead transcription factor 01-regulated the oxidative stress response
}

\author{
Hongkun Wang ${ }^{1}$, Yanhui Zhang ${ }^{1}$, Fangfang Xia ${ }^{2}$, Wei Zhang ${ }^{3}$, Peng Chen ${ }^{4}$ and Guoan Yang ${ }^{3^{*}}$ (D)
}

\begin{abstract}
Background: Podocyte plays an important role in maintaining the integrity and function of the glomerular filtration barrier. Various studies reported that forkhead transcription factor (Fox) O1 played a key role in anti-oxidative signaling. This study aimed to investigate the role of Stat1 in high glucose (HG) -induced podocyte injury.

Methods: Under normal glucose, hypertonic and HG stimulated podocyte conditions, cell counting kit-8 (CCK-8) assay, flow cytometry and western blot and quantitative real-time polymerase chain reaction (qRT-PCR) were respectively carried out to determine cell viability, apoptosis, reactive oxygen species (ROS) production and related genes expressions. We then respectively used silent Stat1, simultaneous silencing Stat1 and FoxO1 and over-expression of FoxO1, to observe whether they/it could reverse the damage of podocytes induced by HG.

Results: High glucose attenuated cell survival and promoted cell apoptosis in MPC-5 cells at the same time, and it was also observed to promote the protein expression of Stat1 and the FoxO1 expression inhibition. Silencing Stat1 could reverse HG-induced podocytes injury. Specifically, siStat1 increased cell viability, inhibited cell apoptosis and attenuated ROS level in a high-glucose environment. Cleaved caspase-3 and pro-apoptosis protein Bax was significantly downregulated, and anti-apoptosis protein $\mathrm{BCl}-2$ was up-regulated by siStat1. The antioxidant genes Catalase, MnSOD, NQO1 and $\mathrm{HO} 1$ were up-regulated by siStat1. We found that silencing FoxO1 reversed the protective effect of siStat1 on the HG-induced podocytes injury.

Conclusions: Silencing Stat1 could reverse the effects of high glucose-triggered low cell viability, cell apoptosis and ROS release and the functions of Stat1 might be involved in FoxO1 mediated-oxidative stress in nucleus.
\end{abstract}

Keywords: Stat1, FoxO1, Podocyte, HG, Oxidative stress

\section{Background}

The prevalence of diabetes nephropathy (DN) among diabetic patients is about $20-40 \%$ [1]. DN is one of the microvascular complications of diabetes mellitus and is a main cause of end-stage nephropathy $[2,3]$. The most common clinical feature of DN is progressive proteinuria [4]. The occurrence of proteinuria is closely related to the integrity of glomerular filtration barrier (GFB), which is composed of

\footnotetext{
* Correspondence: guoany_yangga@163.com

${ }^{3}$ Central Laboratory, The First Affiliated Hospital of Baotou Medical College Inner Mongolia University of Science and Technology, No.41 Linyin Road, Kundulun District, Baotou 014010, Inner Mongolia, China

Full list of author information is available at the end of the article
}

capillary endothelial cells, podocytes and a basement membrane between the two [5]. Podocytes are highly differentiated cells that form the outer layer of the filter membrane [6]. Normal morphology and function of podocytes play important roles in proteinuria formation and renal function maintenance [7]. The pathogenesis of DN involved factors such as hemodynamic changes, metabolic disorders, cytokines, inflammatory responses, oxidative stress, autophagy and epithelial-mesenchymal transition (EMT) [8-10]. The occurrence and development of DN is closely related to oxidative stress [11]. Reactive oxygen species (ROS) is mainly synthesized in mitochondria and is the active product of aerobic metabolism. ROS is an important component

(c) The Author(s). 2019 Open Access This article is distributed under the terms of the Creative Commons Attribution 4.0 International License (http://creativecommons.org/licenses/by/4.0/), which permits unrestricted use, distribution, and reproduction in any medium, provided you give appropriate credit to the original author(s) and the source, provide a link to the Creative Commons license, and indicate if changes were made. The Creative Commons Public Domain Dedication waiver (http://creativecommons.org/publicdomain/zero/1.0/) applies to the data made available in this article, unless otherwise stated. 
of oxidative stress reaction. High glucose stimulation can aggravate oxidative stress, leading to a large accumulation of ROS that is beyond the body's ability to clear the ROS and would therefore exacerbates oxidative stress injury in diabetics [12].

Forkhead transcription factor O1 (FoxO1, FKHR) is a member of the "O" subfamily of the Fox, which also includes three other members, that is, FoxO3a (FKHRL1), FoxO4 (AFX) and FoxO6 [13, 14]. FoxO1 gene is mapped to chromosome 13 and it has 4 functional domains including nuclear localization signal domain (NLS), the transactivation domain (TA), nuclear export signal (NES) and forkhead domain (FKH) [15-17]. FoxO1 is widely distributed in vivo, and as a key regulatory factor, it plays an important role in regulating glycolipid metabolism, transcriptional translation, antioxidant stress and cell cycle in the transcriptional process [18-20]. FoxO transcription factors are key mediators of oxidative stress and are activated by various cellular stress stimuli [19]. Recent studies have found that Fox protein family, such as FoxO1, FoxO3, FoxO4, were associated with oxidative stress [21-23].

Stat is a cytoplasmic protein that binds to target gene regulatory region DNA, and it regulates cell transcription. Seven members (Stat1, 2, 3, 4, 5 $\alpha, 5 \beta$ and 6) of mammalian Stat protein family are mainly composed of N-terminal oligomerization domain (NT), DNA binding domain (DBD), Src homology 2 domain (SH2) and C-terminal transcriptional activation region (TAD) [24, 25]. Stat1, the first member discovered in the family of Stat proteins, was corroborated to have the function of regulating physiological process, for example, immune response, proliferation, apoptosis and cell survival [26-28]. Recently, Stat1 was also found to act as a tumor inhibitor in liver cancer, esophageal squamous cell carcinoma, breast cancer and colorectal cancer [29-31].

In this study, we aim to investigate the role of Stat1 in high glucose-induced podocytes injury, and whether this effect was related to FoxO1 mediated oxidative stress.

\section{Methods}

\section{Cell culture}

Immortalized mouse podocyte MPC-5 cell was obtained from Research Facilities of PUMCH Cell Bank (Beijing, China). Undifferentiated MPC-5 cells were cultured in DMEM medium (Gibco, Thermo Fisher, USA) with 10 $\mathrm{U} / \mathrm{ml}$ mice recombinant $\gamma$ - interferon (Peprotech Inc., USA) in an incubator with $5 \% \mathrm{CO}_{2}$ at $33^{\circ} \mathrm{C}$. Podocytes were cultured for 2 weeks in the DMEM medium with mouse recombinant $\gamma$-interferon at $37^{\circ} \mathrm{C}$ to induce cell differentiation and maturation.

\section{Immunofluorescence}

The podocytes were plated in a $24-$ well plate. When $40 \%$ confluent, the cells were fixed, infiltrated and blocked.
Each slide was incubated with anti-nephrin (ab216341, 1:500, Abcam, USA) and anti-podocin (ab50339, 1:500, Abcam, USA) at $4{ }^{\circ} \mathrm{C}$ overnight. Then the slides were washed three times with PBS and incubated with Alexa Fluor 488 labeled goat anti-rabbit IgG (A0423, 1:100, Beyotime, Shanghai, China) for $45 \mathrm{~min}$ at room temperature. Finally, cells were observed under a confocal laser scanning microscope (Olympus, FV 1000, Center Valley, PA, USA).

\section{Cell counting kit-8 (CCK-8)}

In the presence of electron-coupled carrier 1-methoxy PMS, 2-(2-methoxyl-4-nitrobenzene)-3-(4-nitrophenyl)-5(2, 4-disulfonylbenzene)-2 h-tetrazole monosodium salt can be reduced by dehydrogenase in mitochondria to produce soluble orange-yellow formazan. The color degree is inversely proportional to cytotoxicity and the color of CCK- 8 is closed to the medium with phenol red. Cells were seeded in 96-well plate in DMEM medium at a density of $1 \times 10^{4}$ cells/well and disposed with different regents. Next, $10 \mu \mathrm{l}$ CCK- 8 were added into the cells for additional $2 \mathrm{~h}$ at $37^{\circ} \mathrm{C}$ in humidified $5 \% \mathrm{CO}_{2}$. The optical density (OD) was measured at $450 \mathrm{~nm}$ wave (Thermo Fisher, Massachusetts, USA).

\section{Carboxyfluorescein diacetate succinimidyl ester (CFSE) assay}

The detached cell suspension of $10 \times 10^{6}$ cells $/ \mathrm{ml}$ was incubated with $5 \mu \mathrm{M}$ CFSE (C1031, Beyotime, Shanghai, China) in PBS for $15 \mathrm{~min}$ at $37^{\circ} \mathrm{C}$. Followed by washing with PBS for two times, the CFSE-labeled target cells were re-suspended and incubated for $48 \mathrm{~h}$ at $37^{\circ} \mathrm{C}$ and $5 \% \mathrm{CO}_{2}$. The fluorescence intensity was measured using

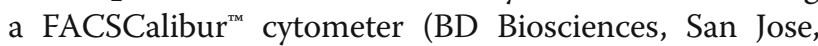
CA, USA).

\section{Cell transfection}

Silencing/over-expressing FoxO1 (sc-425179), silencing Stat1 (sc-44124) and empty control plasmids (sc-37007) were purchased from Santa Cruz Biotechnology (Santa Cruz, CA, USA). MPC-5 cells were seeded in 6-well plate $\left(1.0 \times 10^{5}\right)$ for $24 \mathrm{~h}$ prior to transfection. Transient transfection was operated using lipofectamine 3000 (Invitrogen, USA) according to standard protocol. A total of $20 \mu \mathrm{M}$ si-/over-expressing-RNA and empty control plasmids were respectively transfected using $3.75 \mu \mathrm{l}$ lipofectamine 3000 diluted in Opti-MEM and incubated at room temperature for $15 \mathrm{~min}$. After being cultured for $6 \mathrm{~h}$, the cells was transferred into DMEM medium containing 10\% FBS and maintained for another $48 \mathrm{~h}$.

\section{Flow cytometry}

Cells apoptosis was assessed by flow cytometry with Annexin V-FITC/PE staining kit (Meilun Biotechnology 
Table 1 Primers used in qRT-PCR

\begin{tabular}{lll}
\hline Gene & Primer & Sequence \\
\hline Stat1 & Forward & 5'-GAACTACCCAGAATGCC -3' \\
& Reverse & 5'-CTITCCACCACAAACGAG - 3' \\
FoxO1 & Forward & 5'-CAGCAAATCAAGTTATGGAGGA - 3' \\
& Reverse & 5'-CTGAGAGGAGGGGTGTACTAT - 3' \\
Catalase & Forward & 5'-GAATTCGTTAATAAAGAT - 3' \\
& Reverse & 5'-GTCGACTACTITTCTITIT - 3' \\
MnSOD & Forward & 5'-GGCCAAGGGAGATGTTACAA - 3' \\
& Reverse & 5'-GCTTGATAGCCTCCAGCAAC-3' \\
NQO1 & Forward & 5'-CAGCCAATCAGCGTCGGTA-3' \\
& Reverse & 5'-CTTCATGGCGTAGTTGAATGATGTC-3' \\
HO1 & Forward & 5'-TGCAGGTGATGCTGACAGAGG-3' \\
& Reverse & 5'-GGGATGAGCTAGTGCTGATCTGG-3' \\
& Forward & 5'-TGTGTCCGTCGTGGATCTGA-3' \\
GAPDH & Reverse & 5'-TTGCTGTGAAGTCGCAGGAG-3' \\
& &
\end{tabular}

Co., LTD, Dalian, China). Cells were washed twice using washing buffer, and the suspension was cultured with Annexin V and propidium iodide (PI, Yeasen Biotechnology Co., Ltd., Shanghai, China) in the dark at $25^{\circ} \mathrm{C}$ for $15 \mathrm{~min}$. Binding buffer was added to each well. The samples were analyzed by flow cytometry. Cells were identified by Annexin V-FITC/PI double fluorescent staining: unlabeled viable cells, PI stained cells (necrotic cells), Annexin V-FITC bounded cells (early apoptotic cells) and double-labeled cells (late apoptotic cells).

The Intracellular ROS levels were measured using 2, 7dichlorodi- hydrofluorescein diacetate (DCFH-DA, SigmaAldrich, St Louis, MO, USA) by a flow cytometer. Cells were seeded in a 6-well plate. The cells were exposed to reagents for $24 \mathrm{~h}$ when cell confluence reached $70-80 \%$. $10 \mu \mathrm{M}$ DCFDA containing $1 \mathrm{ml}$ phosphate buffer saline (PBS) were added to the cells at room temperature for 20 $\mathrm{min}$, and the resulting DCF fluorescence was measured by flow cytometry [27].

\section{A}

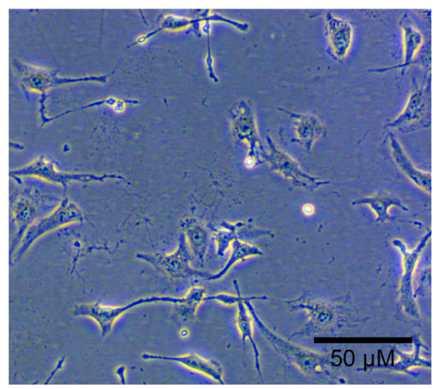

Undifferentiated (400x)

\section{B}

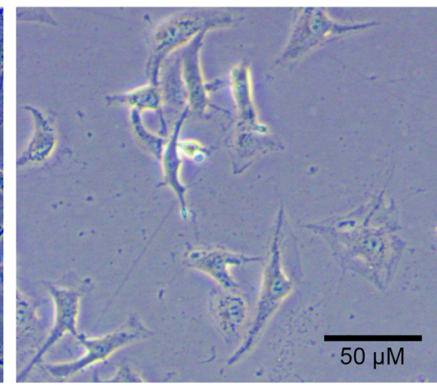

Differentiated (400x)

C
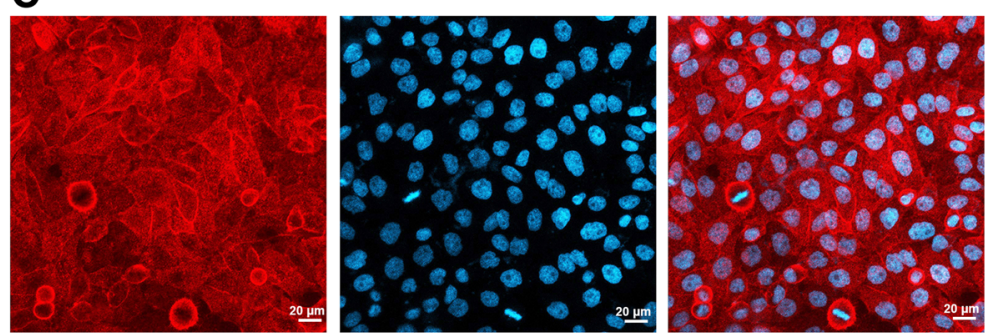

nephrin expression (400x)
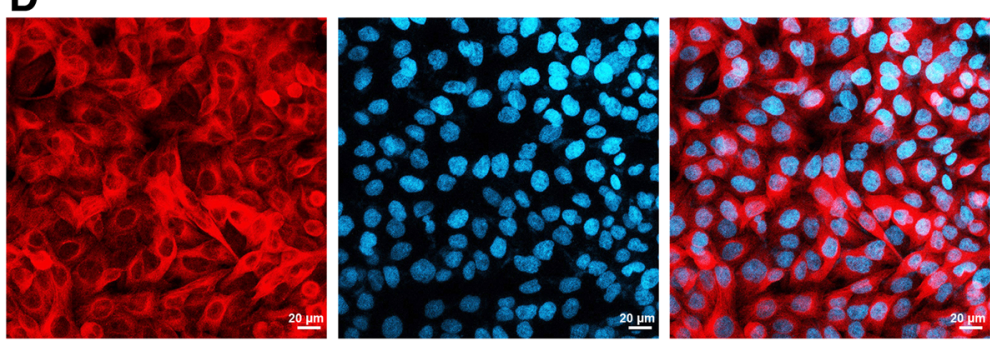

podocin expression (400x)

Fig. 1 Morphological observation of MPC-5 cells (400x). a Under the condition of undifferentiated. b Under the condition of differentiated. c Immunofluorescence was used to detect the nephrin expression in the cytoplasm of podocytes. $\mathbf{d}$ Immunofluorescence was used to detect the podocin expression in the cytoplasm of podocytes 


\section{Quantitative real-time polymerase chain reaction (qRT-} PCR)

Stat1, FoxO1, Catalase, MnSOD, NQO1 and HO1 were detected by performing qRT-PCR in different groups. Total RNA was isolated from cultured MPC- 5 cells by Trizol (Invitrogen, USA) according to the manufacturer's protocol. Reverse transcription was performed with OrimeScript $^{\text {tm }}$ RT reagent kit (TaKaRa, Otsu, Shiga, Japan) at $37^{\circ} \mathrm{C}$ for $15 \mathrm{~min}$ and at $98^{\circ} \mathrm{C}$ for $5 \mathrm{~min}$. cDNA was amplified using SYBR Fast qPCR Mix (Invitrogen, USA) and cycle was set as follows: a pre-denaturation at $95^{\circ} \mathrm{C}$ for $10 \mathrm{~min}$, followed by 40 cycles of denaturation at $95^{\circ} \mathrm{C}$ for $15 \mathrm{~s}$, annealing/elongation at $60^{\circ} \mathrm{C}$ for $1 \mathrm{~min}$. All primers were assisted in the synthesis (Sangon Biotech, Shanghai, China). The primer sequences were listed in Table 1. Amplified products were electrophoresed through $2 \%$ agarose gels. The amount of RNA was calculated using the $2^{-\Delta \Delta C T}$ method, and GAPDH served as an internal control [32].

\section{Western blotting analysis}

Cellular proteins were extracted from cultured MPC-5 cells by RIPA lysis buffer (Thermo Scientific, Pierce, Rockford, IL, USA). The concentration of proteins was determined using Bradford method (Amresco, USA). Aliquots of supernatant containing proteins were mixed with loading buffer, and the samples were subjected to $12 \%$ SDS-PAGE gel. Next, the resolved proteins were transferred onto a polyvinylidene difluoride membrane, and blots were blocked in $1 \%$ milk, TBS, $0.1 \%$ Tween-20. Proteins were incubated with following primary antibodies: rabbit anti-Stat1 antibody (phospho S727, ab109461, 1:1000, Abcam, USA), anti-FoxO1 antibody (Ab-256, SAB4300410, 1:1000, Merck, Germany); anti-cleaved caspase-3 antibody (ab2302, 1:1000, Abcam, USA), anti-Bcl-2 (ab32124, 1: 1000, Abcam, USA), anti-Bax (ab32503, 1:1000, Abcam, USA); anti-Catalase (ab16731, 1:2000, Abcam, USA), antiMnSOD (orb94946, 1:1000, Biorbyt, Britain), anti-NQO1

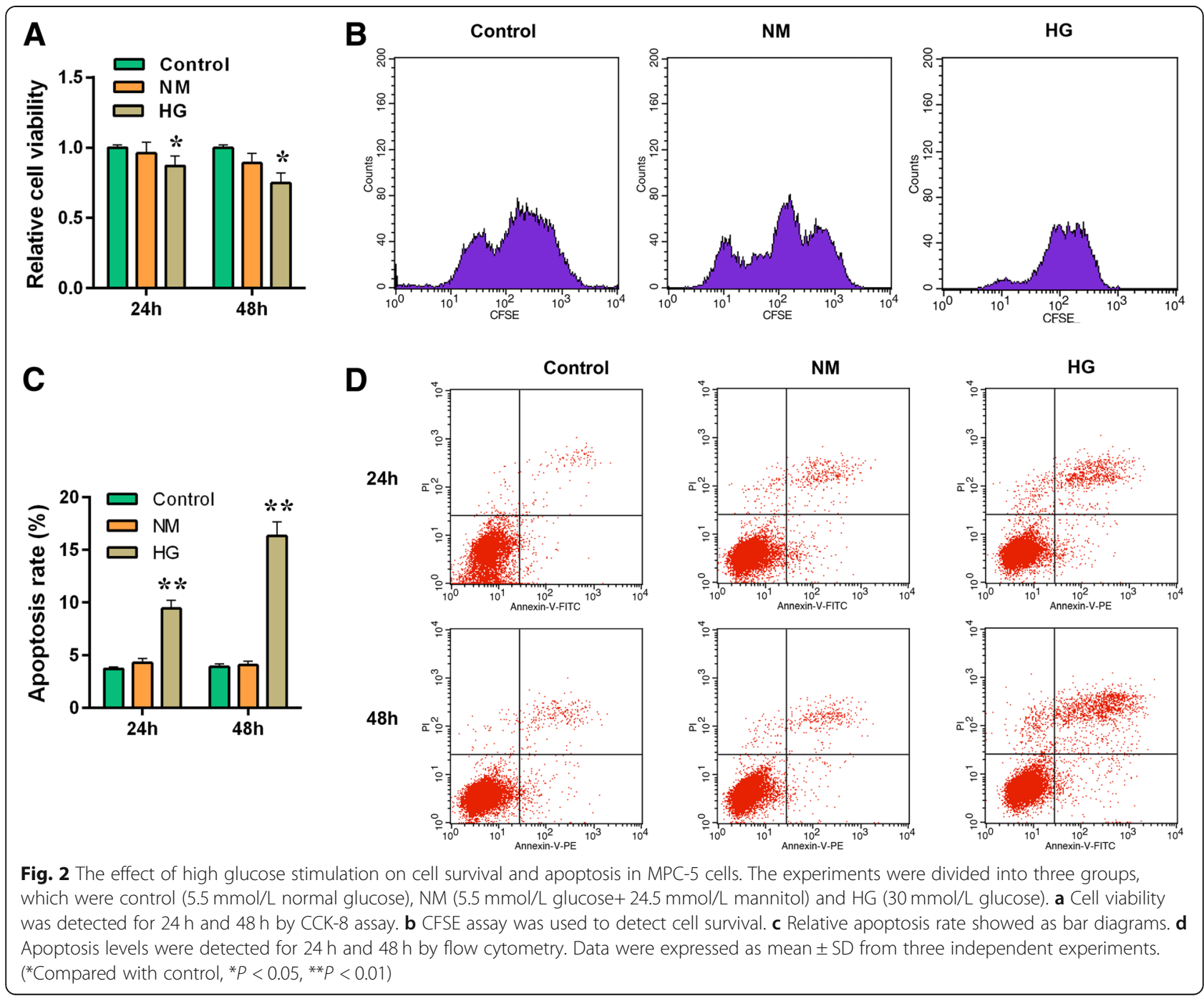


antibody (ab34173, 1:1000, Abcam, USA), anti-HO1 antibody (SMC-131D-HRP, 1:1000, StressMarq, Canada); anti-Lamin B1 antibody (ab16048, 1:1000, Abcam, USA), anti-Tubulin antibody (ab7291, 1:1000, Abcam, USA) and anti-GAPDH antibody (ab9485, 1:2500, Abcam, USA). The proteins were then washed in TBST for $10 \mathrm{~min}$ and incubated with the HRP-conjugated goat anti-Rabbit IgG (Protein tech, USA) as secondary antibodies. The blots were developed with enhanced chemiluminescent (ECL; Thermo Fisher Scientific, Inc.). The protein signal of immunoblot analysis was developed using NBT/BCIP system (Roche, Switzerland). The quantification of proteins expressions of were performed by using Quantity one (BioRad, USA).

\section{Statistical analysis}

Statistical analysis was detected by Prism Graphpad version 6.0 software. All data were presented as mean \pm standard deviation (SD). Differences were performed using one-way analysis of variance (ANOVA) following Turkey's multiple comparison. A $p<0.05$ was considered as statistically significant.

\section{Results}

High glucose affects cell viability and induces cell apoptosis

The MPC-5 cells were observed by an inverted microscope. Cells show signs of fusiform or triangular under the condition of proliferation with $\gamma$-interferon at $33^{\circ} \mathrm{C}$ (Fig. 1a). After being passaged, the cells ceased to proliferate, and they grew larger, gradually differentiated and matured. The podocytes began to protrude from cytoplasm, forming of the coarse main protrusions and finger-like secondary foot processes (Fig. 1b). Moreover, nephrin and podocin were expressed in the cytoplasm of podocytes (Fig. 1c and d).

To understand the effect of high glucose $(30 \mathrm{mmol} / \mathrm{L})$ stimulation in MPC-5 cells, the cell viability and apoptosis were detected by respectively performing CCK- 8 and flow cytometry for 24 and $48 \mathrm{~h}$. The result showed that mannitol $(24.5 \mathrm{mmol} / \mathrm{L})$ produced limited effect on cell viability $(P>$ $0.05)$ while high glucose exerted an inhibitory effect on cell viability (Fig. $2 \mathrm{a}, P<0.05$ ), in concert with the results of CFSE assay (Fig. $2 \mathrm{~b}, P<0.05)$. Moreover, high glucose $(30 \mathrm{mmol} / \mathrm{L})$ stimulation aggravated cell apoptosis level both at $24 \mathrm{~h}$ and $48 \mathrm{~h}$ compared to control $(5.5 \mathrm{mmol} / \mathrm{L}$ glucose treatment) or $\mathrm{NM}$ group $(5.5 \mathrm{mmol} / \mathrm{L}$ glucose $+24.5 \mathrm{mmol} / \mathrm{L}$ mannitol
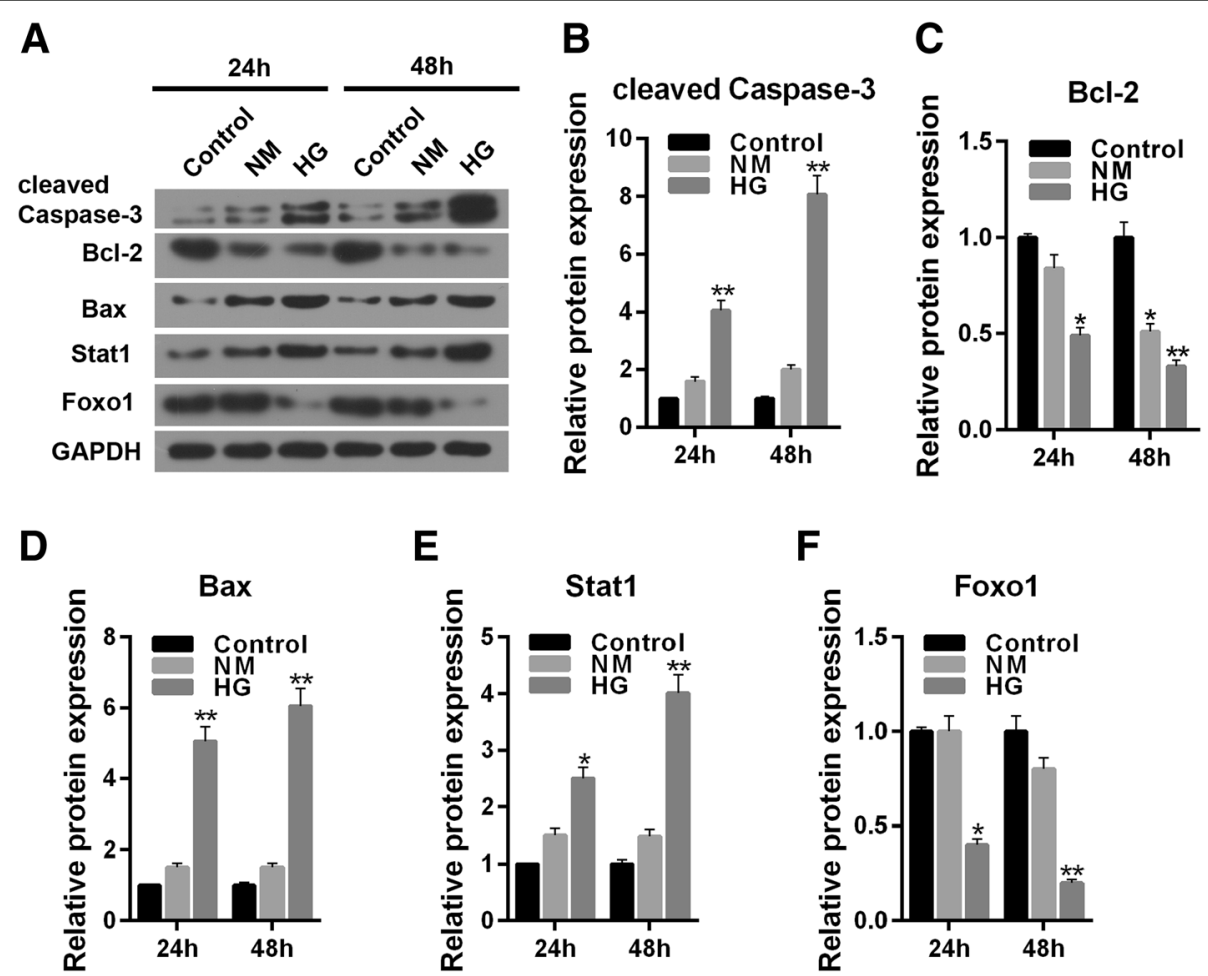

Fig. 3 High glucose affects the protein expression of apoptosis related, Stat1 and FoxO1 in MPC-5 cells. The experiments were divided into three groups, which were control (5.5 mmol/L normal glucose), NM (5.5 mmol/L glucose+ $24.5 \mathrm{mmol} / \mathrm{L}$ mannitol) and HG (30 mmol/L glucose). a The cleaved caspased-3, BCl-2, Bax, Stat1 and FoxO1 protein levels were detected by western blot in MPC-5 cells. $\mathbf{b}$ Relative protein expression of cleaved caspased-3 showed as bar diagrams. c Relative protein expression of Bcl-2 showed as bar diagrams. $\mathbf{d}$ Relative protein expression of Bax showed as bar diagrams. e Relative protein expression of Stat1 showed as bar diagrams. $\mathbf{f}$ Relative protein expression of FoxO1 showed as bar diagrams. GAPDH served as an internal control. Data were expressed as mean \pm SD from three independent experiments. ${ }^{*}$ Compared with control, $\left.{ }^{*} P<0.05,{ }^{* *} P<0.01\right)$ 
treatement) (Fig. 2c and d, $P<0.01$ ). The apoptosis relatedgenes were also assessed by carrying out western blot. The normal glucose and hypertonic group had no significant differences in cleaved caspase-3, Bcl-2 and Bax proteins level. Compared with control, high glucose could not only clearly up-regulate the protein expressions of cleaved caspase-3 and Bax (Fig. 3a, b and d, $P<0.01$ ), but also significantly downregulated the expression of $\mathrm{Bcl}-2$ protein (Fig. $3 \mathrm{a}$ and c, $24 \mathrm{~h}$, $P<0.05 ; 48$ h, $P<0.01$ ).

\section{High glucose affects the protein expression of Stat 1 and FoxO1}

To determine the effect of high glucose on the expressions of Stat1 and FoxO1, the proteins levels were detected by performing western blot. The effects of high glucose on Stat 1 and FoxO1 were realized in a time- dependent manner. High glucose increased the protein level of Stat1 significantly (Fig. 3a and e, $48 \mathrm{~h}, P<0.01$ ) and sharply decreased the expression of FoxO1 protein in $48 \mathrm{~h}$ (Fig. 3a and $\mathrm{f}, P<0.01)$.

Silencing Stat 1 reverses the effect of reduced cell viability and pro-apoptosis by high glucose

Our study has shown that high glucose increased the expression of Stat1. Silent Stat1 plasmid was transfected into MPC-5 cells to help us explore the role of silencing Stat1. We found that siStat1 could recover the cell viability resulted from high glucose injury
A

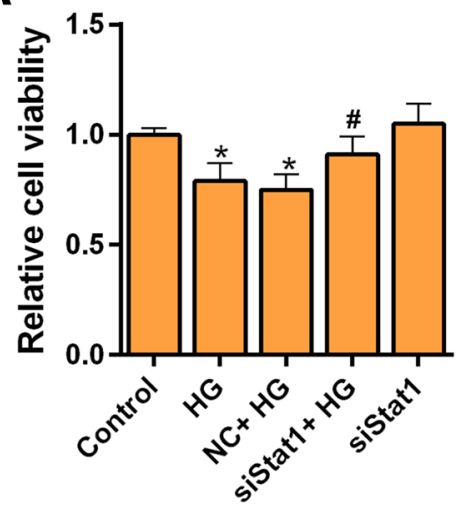

B

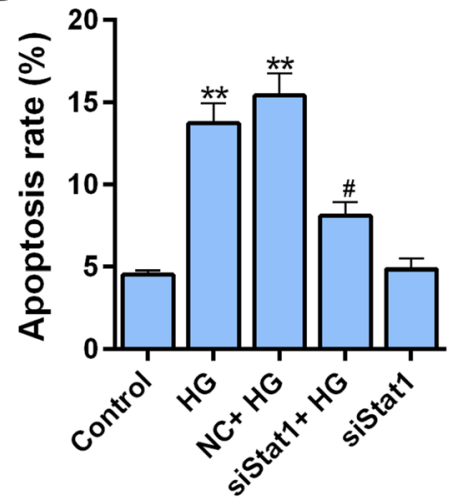

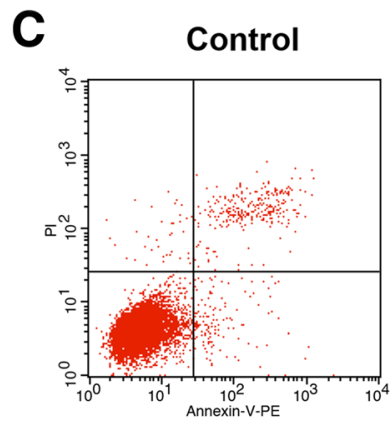

HG
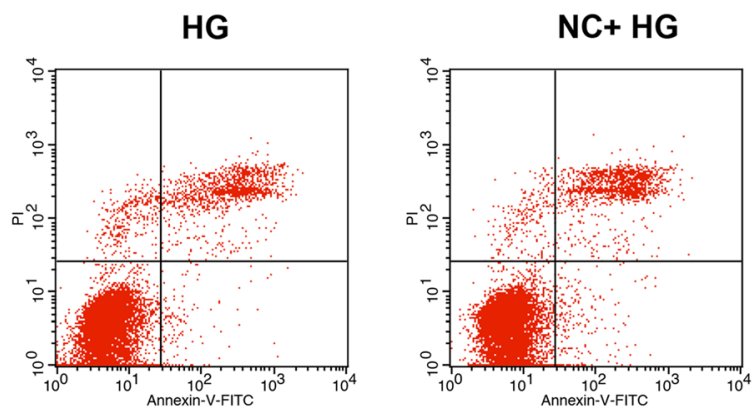

siStat1+ HG

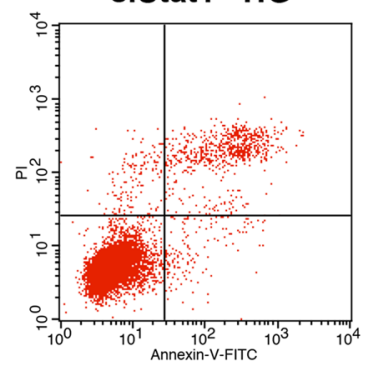

siStat1

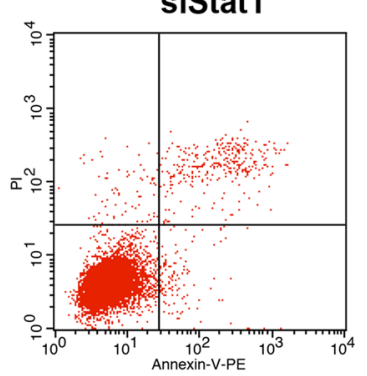

Fig. 4 Silencing Stat1 reverses the effect of cell viability and apoptosis by high glucose. The experiments were divided into five groups, which were control, HG $(30 \mu \mathrm{M}), \mathrm{NC}+\mathrm{HG}$ (Negative siRNA + $30 \mu \mathrm{M} \mathrm{HG}$ ), siStat1 + HG (Stat1 siRNA + $30 \mu \mathrm{M} \mathrm{HG)}$ and SiStat1 (Stat1 siRNA). a Cell viability was detected by CCK-8 assay. b Relative apoptosis rate showed as bar diagrams. c Apoptosis levels were detected by flow cytometry. Data were expressed as mean \pm SD from three independent experiments. ( ${ }^{*}$ Compared with control, ${ }^{\#}$ Compared with HG, ${ }^{*}{ }^{\#} P<0.05,{ }^{* *} P<0.01$ ) 
(Fig. 4a). The apoptosis assay showed that siStat1 significantly attenuated high glucose- induced apoptosis (Fig. 4b and c, $P<0.05)$. Single siStat1 was found to clearly increase the cell viability and down-regulated the apoptosis compared to group high glucose (Fig. 4a, b and c, Cell viability, $P<0.05$; Apoptosis, $P<0.01$ ). The apoptosis related-genes were also detected using western blot, and we found that pro-apoptosis proteins cleaved caspase-3, and that Bax sharply revealed down-regulation expression in the presence of both siStat1 and high glucose simulation (Fig. 5a, b and d, $P<0.05$, Bax, $P<0.01)$. However, the Bcl-2 showed the opposite result that siStat1 could significantly increase expression by reversing a high glucose effect (Fig. 5a and c, $P<0.05)$.
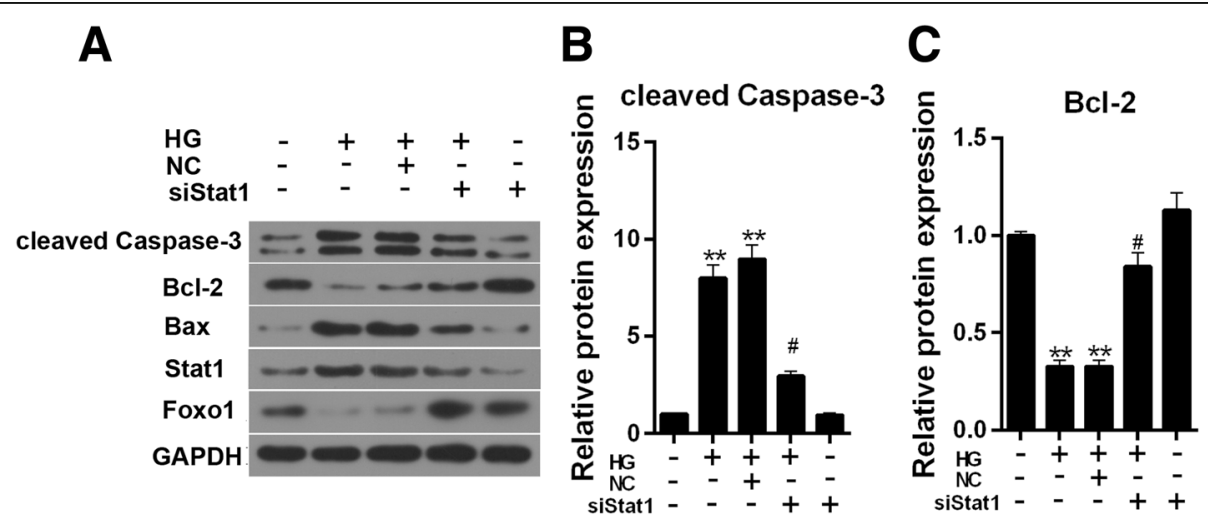

D
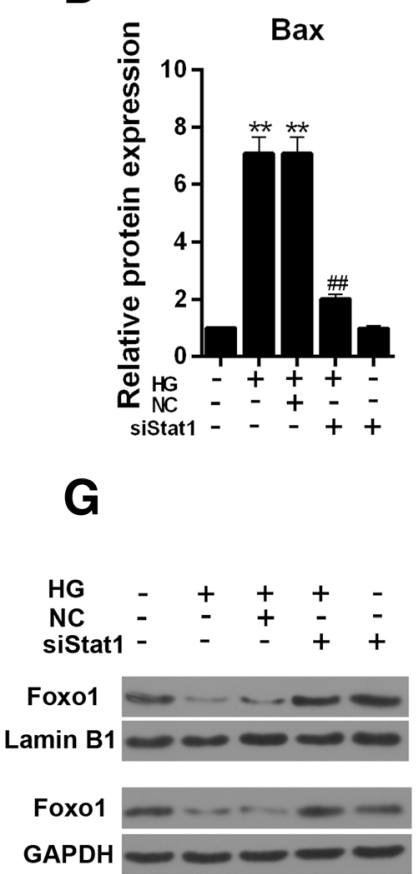

GAPDH
E

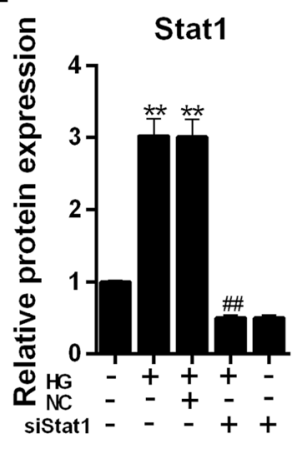

H

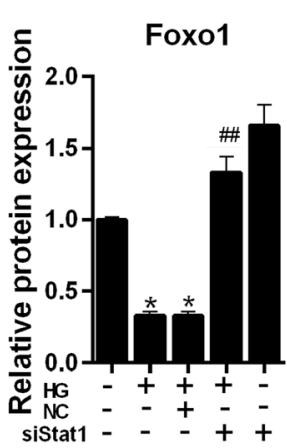

F
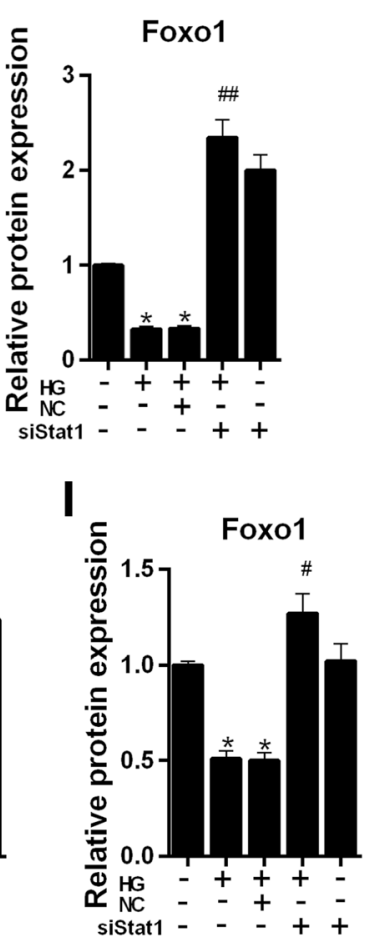

Fig. 5 Silencing Stat1affects the protein expression of apoptosis related, Stat1 and FoxO1 in MPC-5 cells. The experiments were divided into five groups, which were control, HG $(30 \mu \mathrm{M}), \mathrm{NC}+\mathrm{HG}$ (Negative siRNA + $30 \mu \mathrm{M} \mathrm{HG}$ ), siStat1 + HG (Stat1 siRNA + $30 \mu \mathrm{M}$ HG) and SiStat1 (Stat1 siRNA). a The cleaved caspased-3, Bcl-2, Bax, Stat1 and FoxO1 protein levels were detected by western blot in MPC-5 cells. b Relative protein expression of cleaved caspased-3 showed as bar diagrams. c Relative protein expression of Bcl-2 showed as bar diagrams. $\mathbf{d}$ Relative protein expression of Bax showed as bar diagrams. e Relative protein expression of Stat1 showed as bar diagrams. F Relative protein expression of FoxO1 showed as bar diagrams. GAPDH served as an internal control. g The protein expressions of FoxO1 in nucleus and cytoplasm, respectively, Lamin B1 served as a nucleus loading control, GAPDH served as a cytoplasm internal control. $\mathbf{h}$ Relative protein expression of FoxO1 in nucleus showed as bar diagrams. i Relative protein expression of FoxO1 in cytoplasm showed as bar diagrams. Data were expressed as mean \pm SD from three independent experiments. ( ${ }^{*}$ Compared with control, ${ }^{\#}$ Compared with $H G$, ${ }^{*} /{ }^{\#} P<0.05$, ${ }^{* *}{ }^{\# \#} P<0.01$ ) 
Silencing Stat 1 promotes the protein expression of FoxO1 in nucleus

As Fig. 5e shown, in an environment containing high glucose, the protein level of Stat1 was up-regulated (Fig. 5e, $P<0.01)$. The protein expression of Stat1 decreased once siStat1 was added, on the contrary, the protein level of FoxO1 raised (Fig. 5f, $P<0.01$ ).

In order to further explore the expression of FoxO1, the protein level of FoxO1 both in cytoplasm and nucleus was tested. Compared to control, the protein level of FoxO1 significantly decreased after HG treatment in cytoplasm and nucleus environment (Fig. $5 \mathrm{~g}, \mathrm{~h}$ and i, $P<0.05)$. The expression of FoxO1 was increased in HG + siStat1 in nucleus in compared to HG group (Fig. $5 \mathrm{~g}$ and h, Control, $P<0.05$, HG, $P<0.01$ ), however, the cytoplasm FoxO1 showed no clear difference to control (Fig. $5 \mathrm{~g}$ and i, $P>0.05)$.

\section{Silencing Stat1 reduces ROS level and promotes the} expression of antioxidant genes in high glucose injured MPC- 5 cells

The level of ROS was increased noticeably in HG-treated cells, however, the ROS level was alleviated by siStat1 (Fig. 6a and $b, P<0.01)$. We then determined the expressions of antioxidant genes (Catalase, MnSOD, NQO1, HO1) using western blot and qRT-PCR. The western blot analysis showed that these four antioxidant proteins had similar results, which, under a high glucose stimulation, their protein levels was sharply decreased (Fig. 7a-e, Catalase, $P<0.01$, Others, $P<0.05)$. Single siStat1 and siStat1 with HG significantly enhanced the proteins expression of Catalase, MnSOD, NQO1, HO1 $(P<0.01)$. The mRNA levels of Catalase, MnSOD, NQO1, HO1 had basic consistent results (Fig. $7 \mathrm{f}-\mathrm{i})$ with those of proteins.

\section{Over-expressing FoxO1 decreases high glucose induced apoptosis}

The over-expression of FoxO1 was rendered to help understand the role of FoxO1 in HG injured MPC-5 cells. The apoptosis assay showed that over-expressing FoxO1 could significantly inhibit the HG-caused apoptosis (Fig. $8 \mathrm{a}$ and b, $P<0.05$ ).

\section{Over-expressing FoxO1 inhibits ROS production and promotes the expression of antioxidant genes}

The ROS level was tested by flow cytometry. Over-expression of FoxO1 was observed to sharply attenuate the ROS production by high glucose (Fig. $8 \mathrm{c}$ and $\mathrm{d}, P<0.01$ ). The expression of FoxO1 in nucleus was higher in $\mathrm{HG}+$ FoxO1 group than that in high glucose group. The expressions of FoxO1 in

\section{A}

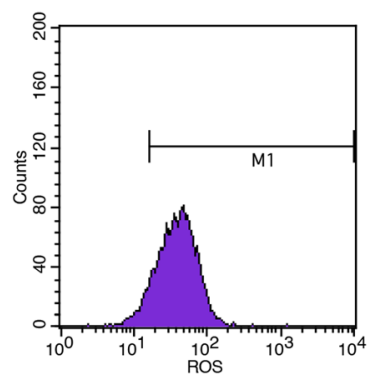

siStat1+ HG

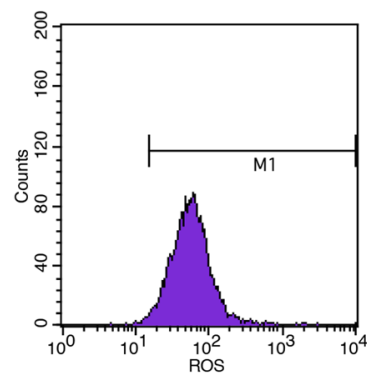

HG

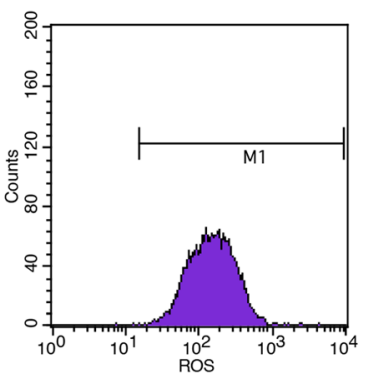

siStat1

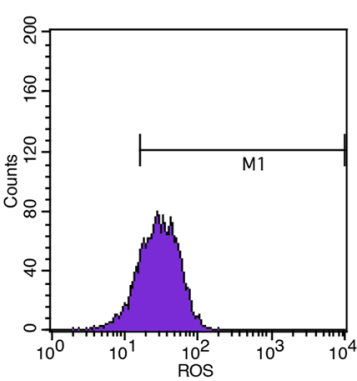

$\mathrm{NC}+\mathrm{HG}$

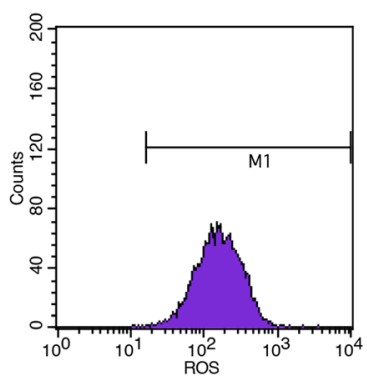

B

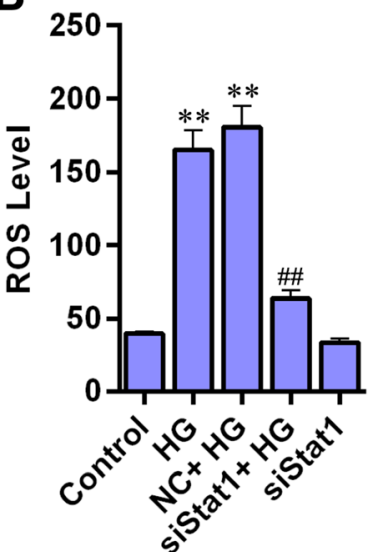

Fig. 6 Silencing Stat1 reduces ROS level in high glucose injured MPC-5 cells. a ROS levels were detected by flow cytometry. b ROS level showed as bar diagrams. Data were expressed as mean \pm SD from three independent experiments. ( ${ }^{*}$ Compared with control, ${ }^{\#}$ Compared with $\mathrm{HG}$, ${ }^{* *}{ }^{\# \# ~} P<0.01$ ) 


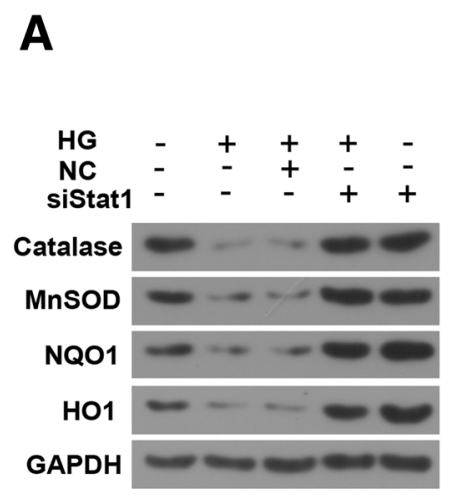

B

D

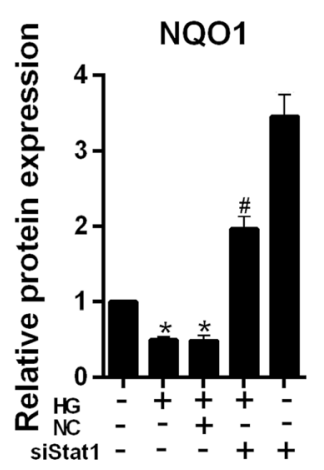

G

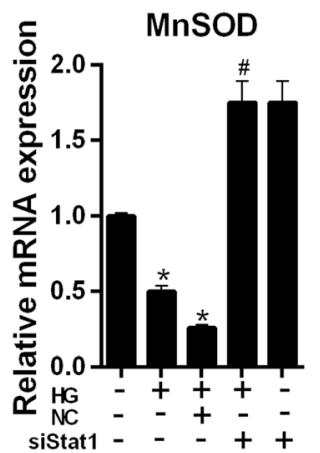

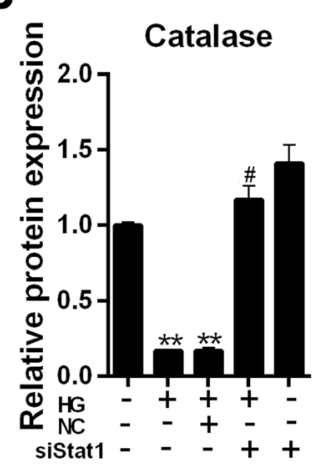

E

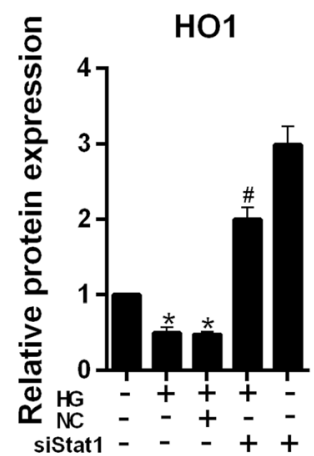

H

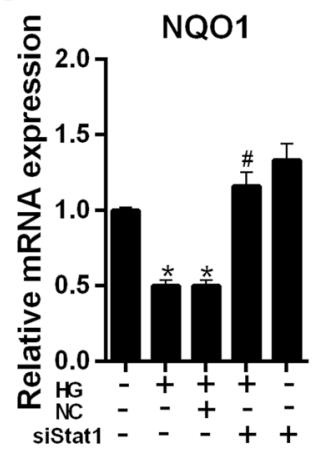

C

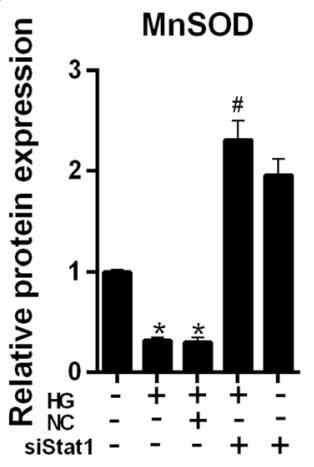

F

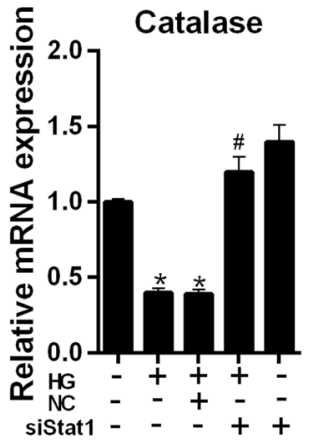

I

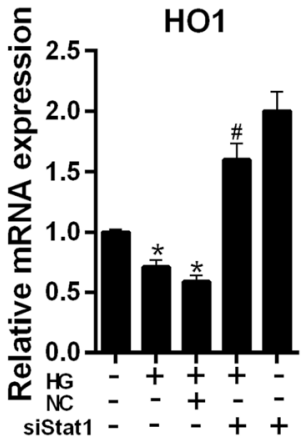

Fig. 7 Silencing Stat1 promotes the expression of antioxidant genes in high glucose injured MPC-5 cells. a The Catalase, MnSOD, NQO1 and HO1 protein levels were detected by western blot in MPC-5 cells. b Relative protein expression of Catalase showed as bar diagrams. c Relative protein expression of MnSOD showed as bar diagrams. $\mathbf{d}$ Relative protein expression of NQO1 showed as bar diagrams. e Relative protein expression of HO1 showed as bar diagrams. $\mathbf{f}$ mRNA expression of Catalase was assessed using qRT-PCR in MPC-5 cells. $\mathbf{g}$ mRNA expression of MnSOD was assessed using qRT-PCR in MPC-5 cells. $\mathbf{h}$ mRNA expression of NQO1 was assessed using qRT-PCR in MPC-5 cells. $\mathbf{i}$ mRNA expression of HO1 was assessed using qRT-PCR in MPC-5 cells. GAPDH served as an internal control. Data were expressed as mean \pm SD from three independent experiments. ( ${ }^{*}$ Compared with control, ${ }^{*}$ Compared with $\left.\mathrm{HG},{ }^{*} /{ }^{*} P<0.05,{ }^{* *} P<0.01\right)$

cytoplasm were increased in HG and HG + FoxO1 groups (Fig. 9a-b). The protein expressions of Catalase, MnSOD, NQO1 and HO1 showed a significant up-regulation in group over-expressing FoxO1 + HG compared to Mock + HG treatment (Fig. 9c and d, MnSOD, $P<0.05$, Others, $P<0.01$ ). The mRNA level of those four genes (Fig. 9e, MnSOD, $P<0.01$, Others, $P<0.05)$ were consistent with proteins.
Silencing FoxO1 reversed the effect of Stat1 silencing on apoptosis and oxidative stress

In order to understand how silencing Stat1 protected high glucose-induced podocytes injury, we transfected silencing Stat 1 and FoxO1 at the same time, and tested apoptosis level by flow cytometry. We found that simultaneous silencing Stat1 and Foxo1 attenuated the anti-apoptosis effect of silencing Stat1 (Fig. 10a and b, $P<0.05$ ). 

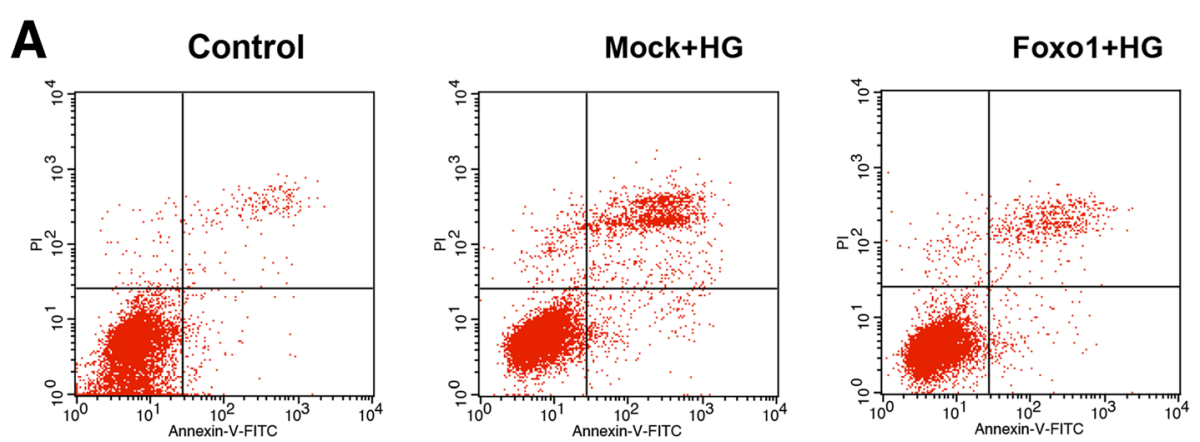

B

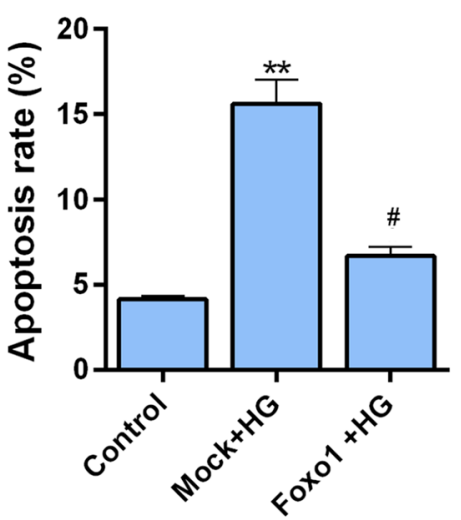

D

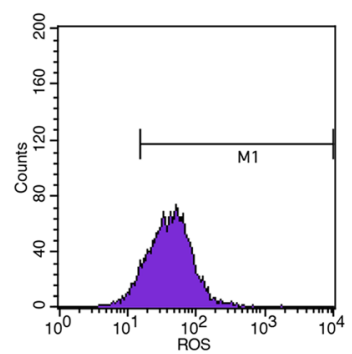

Mock+HG

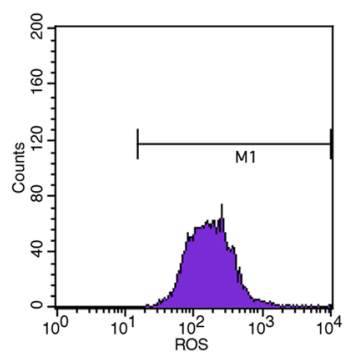

C

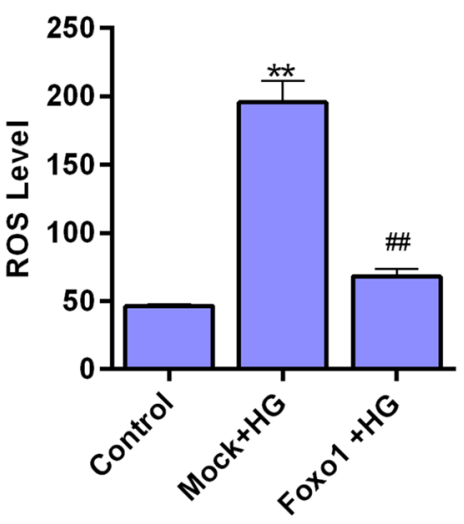

Fig. 8 The effect of over-expressing FoxO1 on apoptosis and ROS level. The experiments were divided into three groups, which were control, Mock + HG and over-expressing FoxO1 + HG. a Apoptosis levels were detected by flow cytometry. $\mathbf{b}$ Relative apoptosis rate showed as bar diagrams. c ROS level showed as bar diagrams. $\mathbf{d}$ ROS levels were detected by flow cytometry. Data were expressed as mean \pm SD from three independent experiments. ( ${ }^{*}$ Compared with control, ${ }^{\#}$ Compared with Mock $+\mathrm{HG},{ }^{\#} P<0.05$, ${ }^{* *}{ }^{\# \#} P<0.01$ )

ROS level increased with simultaneous silencing Stat1 and FoxO1 in HG-induced cells compared to silencing Stat1 (Fig. 10c and d, $P<0.05$ ). Furthermore, the antioxidant genes (Catalase, MnSOD, NQO1, HO1) were also detected by western blot. Our results showed that Simultaneous silencing Stat1 and FoxO1 could significantly inhibited the protein and mRNA expressions of the antioxidant genes (Fig. 11a-e, Catalase, $P<0.05$, Others, $P<0.01$ ) compared to silencing Stat1 in HG induced cells.

\section{Discussion}

Podocytes are highly differentiated cells with complex cytoskeletons [6]. They are the last barrier to glomerular filtration, and they play an important role in maintaining the integrity and function of the glomerular filtration barrier. Therefore, injury and apoptosis of podocytes would affect glomerular function [7, 33]. As previously reported in literature study, high glucose could cause podocytes injury [34-36].

The progression of DN is closely related to oxidative stress [11]. In this study, we used high glucose $(30 \mathrm{mmol} / \mathrm{L})$ to induce podocytes injury. Our results revealed that high glucose attenuated cell viability and promoted cell apoptosis. Stat1 is a member of a family of potential cytoplasmic transcription factors that are activated by cytokines and growth factors, 

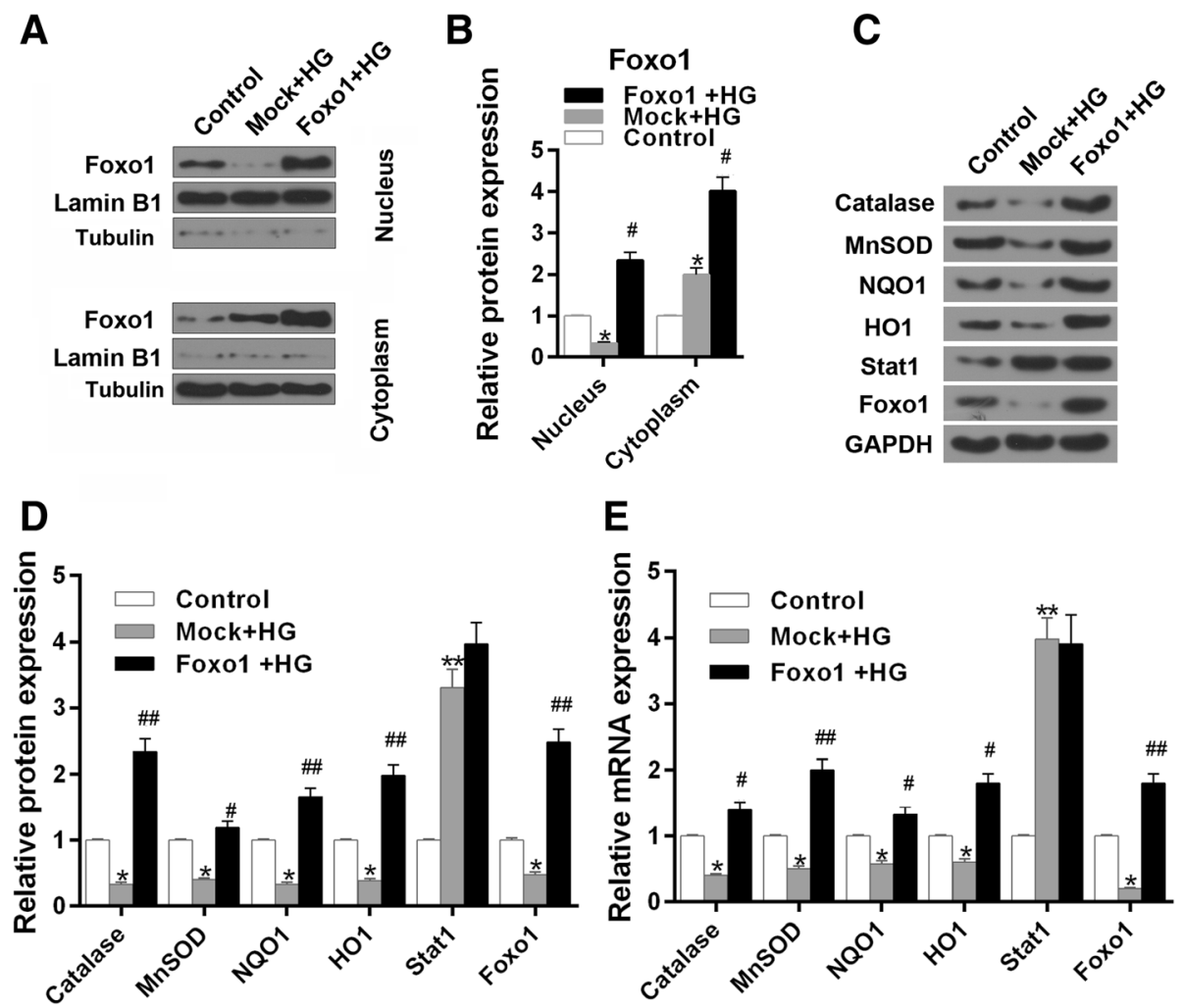

Fig. 9 The effect of over-expressing FoxO1 on the expression of antioxidant genes, Stat1 and FoxO1. The experiments were divided into three groups, which were control, Mock + HG and over-expressing FoxO1 + HG. a The protein expression of FoxO1 in nucleus and cytoplasm, respectively, Lamin B1 served as a nucleus loading control, Tubulin served as a cytoplasm internal control. b Relative protein expressions of FoxO1 in nucleus and cytoplasm showed as bar diagrams. c The Catalase, MnSOD, NQO1, HO1, Stat1 and FoxO1 protein levels were detected by western blot in MPC-5 cells. d Relative protein expression of Catalase, MnSOD, NQO1, HO1, Stat1 and FoxO1 showed as bar diagrams. e mRNA expression of Catalase, MnSOD, NQO1, HO1, Stat1 and FoxO1 were assessed using qRT-PCR in MPC-5 cells. GAPDH served as an internal control. Data were expressed as mean \pm SD from three independent experiments. ( ${ }^{*}$ Compared with control, ${ }^{*}$ Compared with Mock $+\mathrm{HG},{ }^{*} /{ }^{\#} P<0.05,{ }^{*}{ }^{\# \#} P<0.01$ )

which transmit signals from the cell surface to the nucleus [27]. Inhibition of Stat1 was involved in the antioxidant effect of SOCS1 in diabetes [37]. The expression of Stat1 was increased in patients with diabetic nephropathy [38], and the activated STAT1 was increased in high glucose-cultured mesangial cells (MCs) [39]. In addition, as one of the target genes of STAT1, FoxO1 plays a role in oxidant stress [40]. Thus we detected the protein expression of Stat1 and FoxO1. Our results showed that silencing Stat1 could significantly reverse the podocytes injury caused by high glucose. Specifically, siStat1 increased cell viability, inhibited cell apoptosis and attenuated ROS level in a high-glucose environment. Cleaved (active) caspase- 3 is the executioner of apoptosis. The high glucose resulted in the increase of cleaved caspase- 3 and Bax as well as the decreased Bcl-2. Interestingly, we found that mannitol suppressed the $\mathrm{Bcl}-2$ at $48 \mathrm{~h}$. however, we cannot explain the possible reason and it needs further study. Cleaved caspase3 and pro-apoptosis protein Bax was found to be significantly down-regulated, and anti-apoptosis protein $\mathrm{Bcl}-2$ was up-regulated by siStat1 compared to high glucose.
Moreover, the expressions of Catalase, MnSOD, NQO1 and $\mathrm{HO} 1$ were increased by silencing Stat1. As two core antioxidant enzymes, Catalase and MnSOD were reported to be associated with elimination of ROS-mediated injuries [41]. MnSOD, a type of superoxide dismutase in eukaryotic cells [42], can eliminate $\mathrm{O}_{2}^{-}$. and plays an important role in antioxidation, retarding senility and wounding- resistant $[43,44]$. As two important Phase II detoxification enzymes, NQO1 and HO-1 are downstream target genes regulated by Nrf2 [45]. NQO1 can be used as an electron transporter of NADH or NADPH to catalyze the reduction reaction of quinones and alleviate oxidative stress injury [46]. Stat family members could bind to FoxO1, and Stat1 played a negative role in FoxO1 promoter activity [47, 48]. We found that HG treatment decreased the Foxo1 expression in nucleus, and such a result was consistent with a research, which reported that Stat 1 was a suppresser for FoxO1 promoter, and Stat1 can decrease the expression of FoxO1 [49]. The data also showed that Stat1 silencing could significantly increase the expression of FoxO1 in a 
A
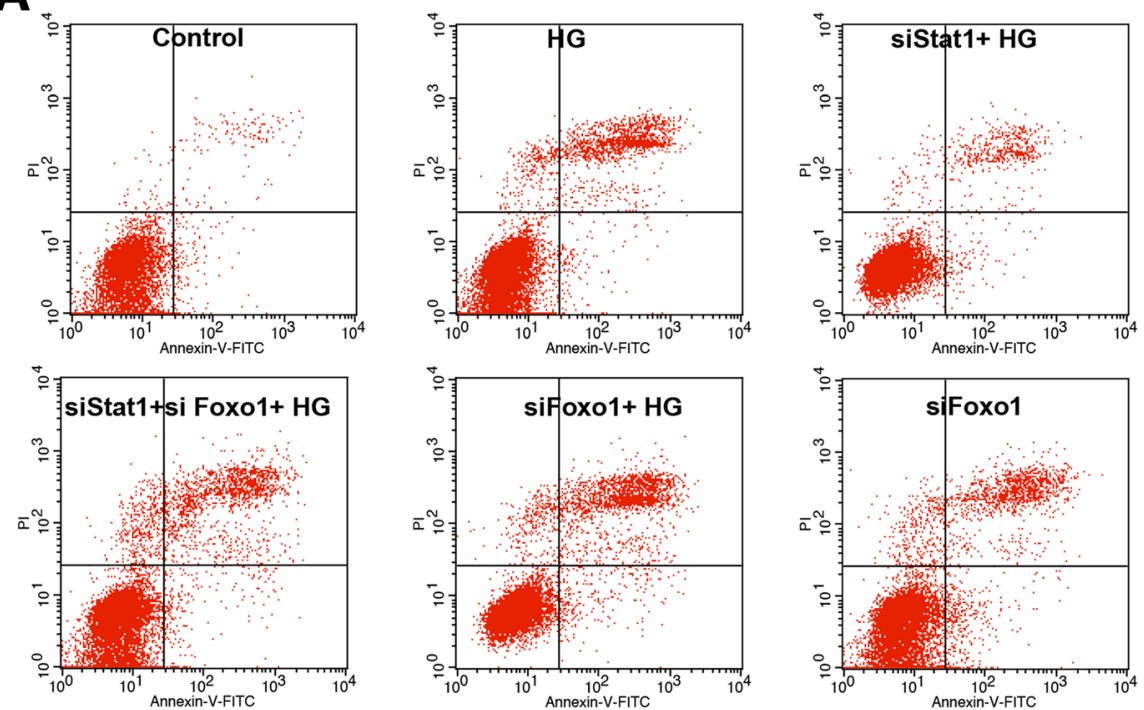

B

C
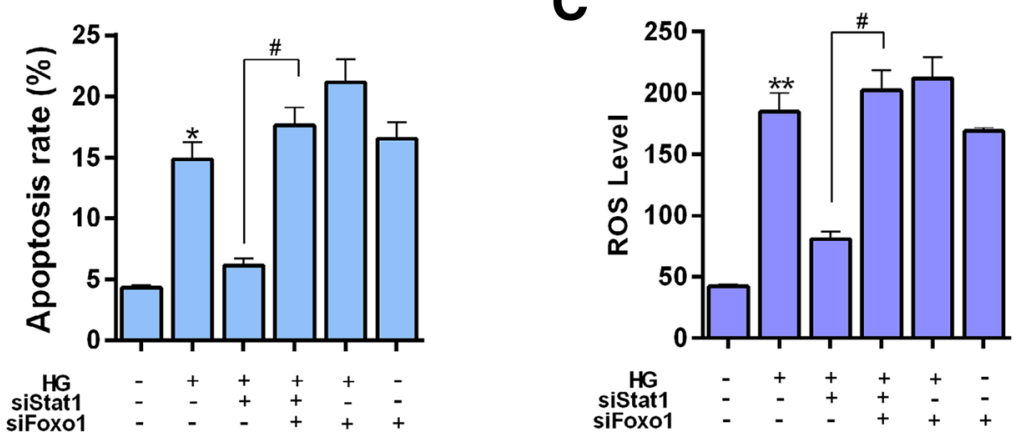

D
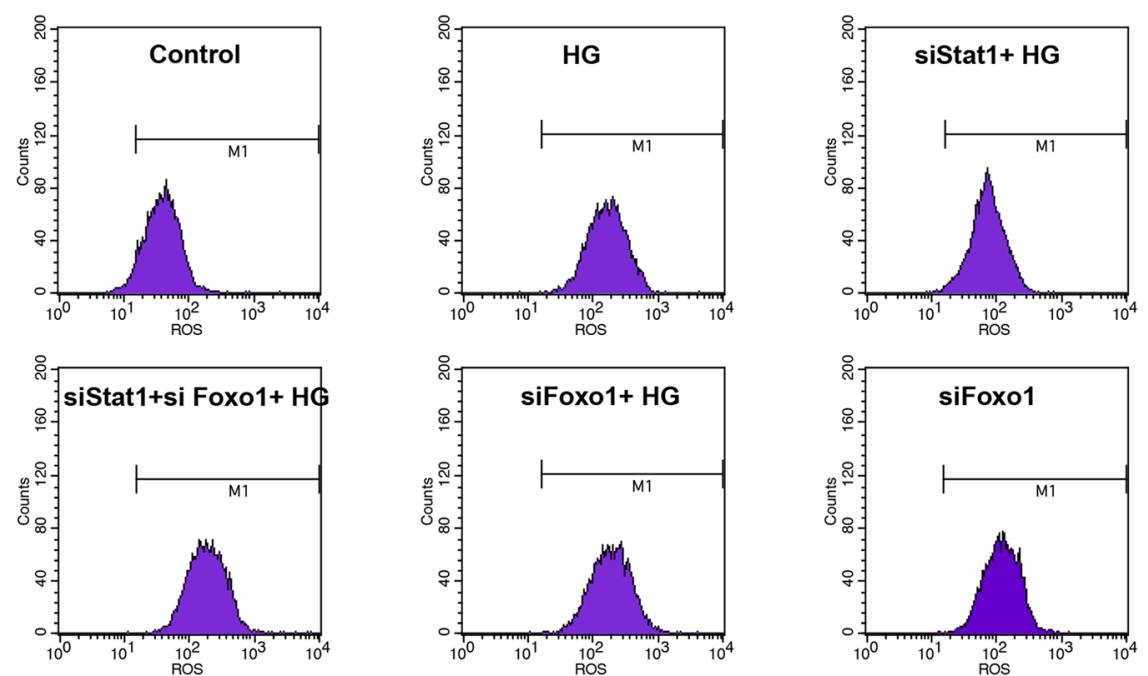

Fig. 10 The effect of simultaneous silencing Stat1 and FoxO1 on apoptosis and ROS level. The experiments were divided into six groups, which were control, HG $(30 \mu \mathrm{M})$, siStat1 + HG (Stat1 siRNA + $30 \mu \mathrm{M} \mathrm{HG})$, siStat1 + siFoxO1 + HG (Stat1 siRNA + FoxO1 siRNA + $30 \mu \mathrm{M}$ HG), siFoxO1 + HG (FoxO1 siRNA $+30 \mu \mathrm{M} \mathrm{HG}$ ) and siFoxO1 (FoxO1 siRNA). a Apoptosis levels were detected by flow cytometry. b Relative apoptosis rate showed as bar diagrams. c ROS level showed as bar diagrams. d ROS levels were detected by flow cytometry. Data were expressed as mean \pm SD from three independent experiments. $\left({ }^{*}\right.$ Compared with control, ${ }^{\#}$ Compared with siStat $\left.1+H G,{ }^{*} /{ }^{*} P<0.05,{ }^{* *} /{ }^{\# \#} P<0.01\right)$ 

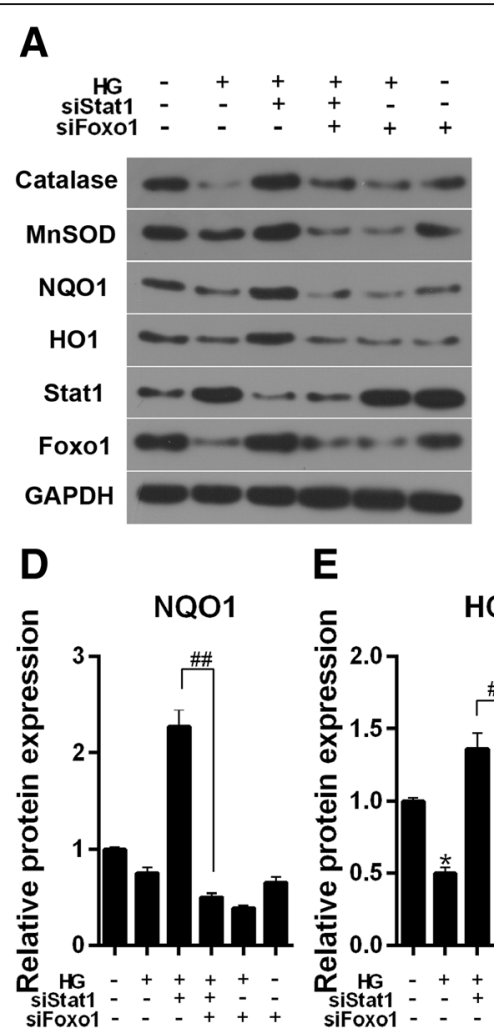

E
B

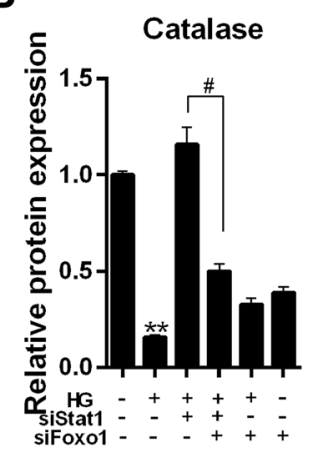

C

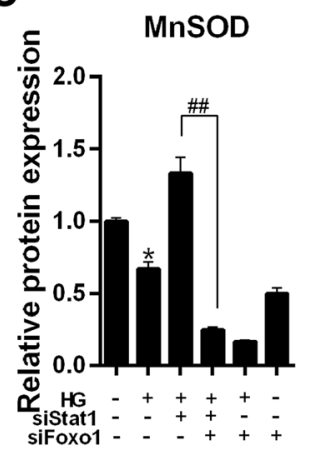

\section{G}

$\mathbf{F}$

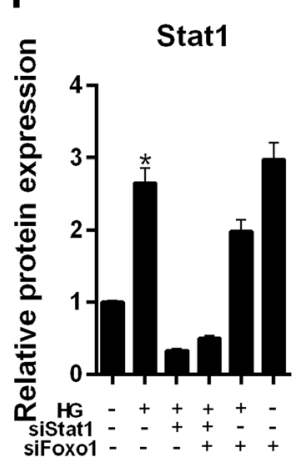

Fig. 11 The effect of simultaneous silencing Stat1 and FoxO1 on the expression of antioxidant genes, Stat1 and FoxO1. The experiments divided were into six groups, which were control, HG $(30 \mu \mathrm{M})$, siStat1 + HG (Stat1 siRNA + $30 \mu \mathrm{M} \mathrm{HG})$, siStat1 + siFoxO1 + HG (Stat1 siRNA + FoxO1 siRNA $+30 \mu \mathrm{M} \mathrm{HG}$ ), siFoxO1 + HG (FoxO1 siRNA + $30 \mu \mathrm{M} \mathrm{HG}$ ) and siFoxO1 (FoxO1 siRNA). a The Catalase, MnSOD, NQO1, HO1, Stat1 and FoxO1 protein levels were detected by western blot in MPC-5 cells. b Relative protein expression of Catalase showed as bar diagrams. $\mathbf{c}$ Relative protein expression of MnSOD showed as bar diagrams. d Relative protein expression of NQO1 showed as bar diagrams. e Relative protein expression of HO1 showed as bar diagrams. $\mathbf{f}$ Relative protein expression of Stat1 showed as bar diagrams. $\mathbf{g}$ Relative protein expression of FoxO1 showed as bar diagrams. GAPDH served as an internal control. Data were expressed as mean \pm SD from three independent experiments. ${ }^{*}$ Compared with control, ${ }^{*}$ Compared with siStat $\left.1+\mathrm{HG},{ }^{*} /{ }^{\#} P<0.05,{ }^{* *} /{ }^{\#} P<0.01\right)$

high-glucose environment. Moreover, the overexpression of Foxo1 decreased the apoptosis and ROS generation generated by high glucose. In addition, the expressions of Catalase, MnSOD, NQO-1 and HO-1 were also higher in $\mathrm{HG}+$ Foxol group than those in HG group.

Simultaneous silencing Stat1 and FoxO1 were used in order to explore whether Stat1 protected podocytes from high glucose injury through Foxo1. We found that down-regulation of FoxO1 increased apoptosis, promoted ROS production and inhibited the expressions of Catalase, MnSOD, NQO-1 and HO-1 compared to siStat1. The results indicated that knockdown of Stat1 protected podocytes from high glucose injury via regulating the expression of FoxO1. Researchers reported that increased transcriptional activity of FoxO1 accounted for alteration in oxidative stress triggered by ROS accumulation $[41,50]$. Moreover, low-level FoxO1 might be related to the reduced transcription of antioxidant enzymes [51]. Thus, our results were consistent with these studies.

\section{Conclusion}

We explored the role of silencing Stat1 on high glucoseinduced podocytes injury, and found that it could vreverse the effect of high glucose- triggered low cell viability, cell apoptosis and increased ROS production, and the functions of Stat1 was related to FoxO1 mediated-oxidative stress.

\section{Abbreviations \\ ANOVA: Analysis of variance; CCK-8: Cell counting kit-8; DBD: DNA binding domain; DN: Diabetes nephropathy; FKH: Forkhead domain; GFB: Glomerular filtration barrier; HG: High glucose; MCs: Mesangial cells; NES: Nuclear export signal; NLS: Nuclear localization signal domain; NT: N-terminal oligomerization domain; OD: Optical density; PBS: Phosphate buffer saline; qRT-PCR: Quantitative real-time polymerase chain reaction; ROS: Reactive oxygen species; SD: Standard deviation; SH2: Src homology 2 domain; TA: Transactivation domain; TAD: Transcriptional activation region}

\section{Acknowledgements}

None.

\section{Authors' contributions}

Substantial contributions to conception and design: HW, GY, YZ. Data acquisition, data analysis and interpretation: FX, WZ, PC. Drafting the article or critically revising it for important intellectual content: GY, FX. Final 
approval of the version to be published: All authors. Agreement to be accountable for all aspects of the work in ensuring that questions related to the accuracy or integrity of the work are appropriately investigated and resolved: $Y Z, W Z$

\section{Funding}

None.

\section{Availability of data and materials}

The analyzed data sets generated during the study are available from the corresponding author on reasonable request.

\section{Ethics approval and consent to participate}

Not applicable.

\section{Consent for publication}

Not applicable.

\section{Competing interests}

The authors declare that they have no competing interests.

\section{Author details}

'Department of Nephrology, The First Affiliated Hospital of Baotou Medical College Inner Mongolia University of Science and Technology, Baotou, China. ${ }^{2}$ Department of Nephrology, North Hospital, Baotou, China. ${ }^{3}$ Central Laboratory, The First Affiliated Hospital of Baotou Medical College Inner Mongolia University of Science and Technology, No.41 Linyin Road, Kundulun District, Baotou 014010, Inner Mongolia, China. ${ }^{4}$ Department of Nutriology, The First Affiliated Hospital of Baotou Medical College Inner Mongolia University of Science and Technology, Baotou, China.

\section{Received: 15 January 2019 Accepted: 9 July 2019}

\section{Published online: 23 July 2019}

\section{References}

1. Dronavalli S, Duka I, Bakris GL. The pathogenesis of diabetic nephropathy. Nat Clin Pract Endocrinol Metab. 2008;4(8):444

2. Norlin J, Fink LN, Kvist PH, Galsgaard ED, Coppieters K. Abatacept treatment does not preserve renal function in the Streptozocin-induced model of diabetic nephropathy. PLoS One. 2016;11(4):e0152315.

3. Yao XM, Liu YJ, Wang YM, Wang H, Zhu BB, Liang YP, Yao WG, Yu H, Wang NS, Zhang XM, et al. Astragaloside IV prevents high glucose-induced podocyte apoptosis via downregulation of TRPC6. Mol Med Rep. 2016;13(6):5149-56.

4. Xing L, Liu Q, Fu S, Li S, Yang L, Liu S, Hao J, Yu L, Duan H. PTEN inhibits high glucose-induced phenotypic transition in podocytes. J Cell Biochem. 2015;116(8):1776-84.

5. Ziyadeh FN, Wolf G. Pathogenesis of the podocytopathy and proteinuria in diabetic glomerulopathy. Curr Diabetes Rev. 2008;4(1):39-45.

6. Chen T, Zheng LY, Xiao W, Gui D, Wang X, Wang N. Emodin ameliorates high glucose induced-podocyte epithelial-mesenchymal transition in-vitro and in-vivo. Cell Physiol Biochem. 2015;35(4):1425-36.

7. Li D, Lu Z, Xu Z, Ji J, Zheng Z, Lin S, Yan T: Spironolactone promotes autophagy via inhibiting PI3K/AKT/mTOR signalling pathway and reduce adhesive capacity damage in podocytes under mechanical stress. Biosci Rep. 2016;36(4):e00355

8. Diez-Sampedro A, Lenz O, Fornoni A. Podocytopathy in diabetes: a metabolic and endocrine disorder. Am J Kidney Diseases. 2011;58(4):637-46.

9. Mega C, de Lemos ET, Vala H, Fernandes R, Oliveira J, Mascarenhas-Melo F, Teixeira F, Reis F. Diabetic nephropathy amelioration by a low-dose sitagliptin in an animal model of type 2 diabetes (Zucker diabetic fatty rat). Exp Diabetes Res. 2011;2011:162092

10. Zhou X, Feng Y, Zhan Z, Chen J. Hydrogen sulfide alleviates diabetic nephropathy in a streptozotocin-induced diabetic rat model. J Biol Chem. 2014;289(42):28827-34

11. Brownlee M. The pathobiology of diabetic complications: a unifying mechanism. Diabetes. 2005;54(6):1615-25.

12. Hakim FA, Pflueger A. Role of oxidative stress in diabetic kidney disease. Med Sci Monit. 2010;16(2):Ra37-48.

13. Eijkelenboom A, Burgering BM. FOXOs: signalling integrators for homeostasis maintenance. Nat Rev Mol Cell Biol. 2013;14(2):83-97.
14. Lee S, Dong HH. FoxO integration of insulin signaling with glucose and lipid metabolism. J Endocrinol. 2017;233(2):R67-r79.

15. Zanella F, Dos Santos NR, Link W. Moving to the core: spatiotemporal analysis of Forkhead box $\mathrm{O}$ (FOXO) and nuclear factor-kappaB (NFkappaB) nuclear translocation. Traffic (Copenhagen, Denmark). 2013; 14(3):247-58.

16. Obsil T, Obsilova V. Structural basis for DNA recognition by FOXO proteins. Biochim Biophys Acta. 2011;1813(11):1946-53.

17. Huang H, Tindall DJ. Dynamic FoxO transcription factors. J Cell Sci. 2007; 120(Pt 15):2479-87.

18. Kandula V, Kosuru R, Li H, Yan D, Zhu Q, Lian Q, Ge RS, Xia Z, Irwin MG. Forkhead box transcription factor 1: role in the pathogenesis of diabetic cardiomyopathy. Cardiovasc Diabetol. 2016:15:44.

19. Ponugoti B, Dong G, Graves DT. Role of forkhead transcription factors in diabetes-induced oxidative stress. Exp Diabetes Res. 2012;2012:939751.

20. Vivar R, Humeres C, Munoz C, Boza P, Bolivar S, Tapia F, Lavandero S, Chiong M, Diaz-Araya G. FoxO1 mediates TGF-beta1-dependent cardiac myofibroblast differentiation. Biochim Biophys Acta. 2016; 1863(1):128-38

21. Essers MA, Weijzen S, de Vries-Smits AM, Saarloos I, de Ruiter ND, Bos JL, Burgering BM. FOXO transcription factor activation by oxidative stress mediated by the small GTPase Ral and JNK. EMBO J. 2004;23(24):4802-12.

22. Lehtinen MK, Yuan Z, Boag PR, Yang Y, Villen J, Becker EB, DiBacco S, de la Iglesia N, Gygi S, Blackwell TK, et al. A conserved MST-FOXO signaling pathway mediates oxidative-stress responses and extends life span. Cell. 2006;125(5):987-1001.

23. Motta MC, Divecha N, Lemieux M, Kamel C, Chen D, Gu W, Bultsma Y, McBurney M, Guarente L. Mammalian SIRT1 represses forkhead transcription factors. Cell. 2004;116(4):551-63.

24. Shuai K, Liu B. Regulation of JAK-STAT signalling in the immune system. Nat Rev Immunol. 2003:3(11):900-11.

25. Benekli M, Baumann H, Wetzler M. Targeting signal transducer and activator of transcription signaling pathway in leukemias. J Clin Oncol. 2009;27(26):4422-32.

26. Kim HS, Lee MS. STAT1 as a key modulator of cell death. Cell Signal. 2007; 19(3):454-65.

27. Butturini E, Cozzolino F, Boriero D, Carcereri de Prati A, Monti M, Rossin M, Canetti D, Cellini B, Pucci P, Mariotto S. S-glutathionylation exerts opposing roles in the regulation of STAT1 and STAT3 signaling in reactive microglia. Free Radic Biol Med. 2018;117:191-201.

28. Ebner FH, Mariotto S, Darra E, Suzuki H, Cavalieri E. Use of STAT1 inhibitors in the treatment of brain I/R injury and neurodegenerative diseases. Cent Nerv Syst Agents Med Chem. 2011;11(1):2-7.

29. Zhang Y, Molavi O, Su M, Lai R. The clinical and biological significance of STAT1 in esophageal squamous cell carcinoma. BMC Cancer. 2014;14:791.

30. Simpson JA, Al-Attar A, Watson NF, Scholefield JH, llyas M, Durrant LG. Intratumoral T cell infiltration, MHC class I and STAT1 as biomarkers of good prognosis in colorectal cancer. Gut. 2010;59(7):926-33.

31. Huang S, Bucana CD, Van Arsdall M, Fidler IJ. Stat1 negatively regulates angiogenesis, tumorigenicity and metastasis of tumor cells. Oncogene. 2002;21(16):2504-12.

32. Du M, Wang Q, Li W, Ma X, Wu L, Guo F, Zhao S, Huang F, Wang H, Qin G. Overexpression of FOXO1 ameliorates the podocyte epithelial-mesenchymal transition induced by high glucose in vitro and in vivo. Biochem Biophys Res Commun. 2016;471(4):416-22.

33. Jefferson JA, Alpers CE, Shankland SJ. Podocyte biology for the bedside. Am J Kidney Dis. 2011;58(5):835-45.

34. Susztak K, Raff AC, Schiffer M, Bottinger EP. Glucose-induced reactive oxygen species cause apoptosis of podocytes and podocyte depletion at the onset of diabetic nephropathy. Diabetes. 2006;55(1):225-33.

35. Jin $Y$, Liu $S, M a ~ Q$, Xiao D, Chen L. Berberine enhances the AMPK activation and autophagy and mitigates high glucose-induced apoptosis of mouse podocytes. Eur J Pharmacol. 2017:794:106-14.

36. Shi JX, Wang QJ, Li H, Huang Q. SIRT4 overexpression protects against diabetic nephropathy by inhibiting podocyte apoptosis. Exp Ther Med. 2017;13(1):342-8.

37. Lopez-Sanz L, Bernal S, Recio C, Lazaro I, Oguiza A, Melgar A, JimenezCastilla L, Egido J, Gomez-Guerrero C. SOCS1-targeted therapy ameliorates renal and vascular oxidative stress in diabetes via STAT1 and PI3K inhibition Lab Investig J Tech Methods Pathol. 2018;98(10):1276-90.

38. Li Y, Zhou H, Li Y, Han L, Song M, Chen F, Shang G, Wang D, Wang Z Zhang W, Zhong M.PTPN2 improved renal injury and fibrosis by 
suppressing STAT-induced inflammation in early diabetic nephropathy. J Cell Mol Med. 2019;23(6):4179-95.

39. Wang JY, Liu S, Qin N, Yang QQ, Guo H, Zhang F, Yin XX. Jak2/Stat1 pathway mediated tetrahydrobiopterin up-regulation contributes to nitric oxide overproduction in high-glucose cultured rat mesangial cells. Can J Physiol Pharmacol. 2015;93(1):81.

40. Shen B, Chao L, Chao J. Pivotal role of JNK-dependent FOXO1 activation in downregulation of kallistatin expression by oxidative stress. Am J Physiol Heart Circ Physiol. 2010;298(3):H1048.

41. Tiwari HS, Misra UK, Kalita J, Mishra A, Shukla S. Oxidative stress and glutamate excitotoxicity contribute to apoptosis in cerebral venous sinus thrombosis. Neurochem Int. 2016;100:91-6.

42. Cheng W, Tung YH, Chiou TT, Chen JC. Cloning and characterisation of mitochondrial manganese superoxide dismutase (mtMnSOD) from the giant freshwater prawn Macrobrachium rosenbergii. Fish Shellfish Immunol. 2006; 21(4):453-66.

43. Wu J, Bao M, Ge D, Huo L, Lv Z, Chi C, Liao Z, Liu H. The expression of superoxide dismutase in Mytilus coruscus under various stressors. Fish Shellfish Immunol. 2017;70:361-71.

44. Jia WC, Liu G, Zhang CD, Zhang SP. Formononetin attenuates hydrogen peroxide ( $\mathrm{H}_{2} \mathrm{O} 2$ )-induced apoptosis and NF-kappaB activation in RGC-5 cells. Eur Rev Med Pharmacol Sci. 2014;18(15):2191-7.

45. Wang C, Liao Y, Wang S, Wang D, Wu N, Xu Q, Jiang W, Qiu M, Liu C. Cytoprotective effects of diosmetin against hydrogen peroxide-induced L02 cell oxidative damage via activation of the Nrf2-ARE signaling pathway. Mol Med Rep. 2018;17(5):7331-8.

46. Brunmark A, Cadenas E, Lind C, Segura-Aguilar J, Ernster L. DT-diaphorasecatalyzed two-electron reduction of quinone epoxides. Free Radic Biol Med. 1987;3(3):181-8.

47. Ono M, Chia DJ, Merino-Martinez R, Flores-Morales A, Unterman TG, Rotwein P. Signal transducer and activator of transcription (Stat) $5 \mathrm{~b}-$ mediated inhibition of insulin-like growth factor binding protein-1 gene transcription: a mechanism for repression of gene expression by growth hormone. Mol Endocrinol (Baltimore, Md). 2007;21(6):1443-57.

48. Luo Y. Transcription factors regulate Forkhead box $\mathrm{O} 1$ gene promoter activity in pancreatic B-cells. Asian Biomedicine. 2011;5(4):433-9.

49. Fiorentino L, Cavalera M, Menini S, Marchetti V, Mavilio M, Fabrizi M Conserva F, Casagrande V, Menghini R, Pontrelli P, et al. Loss of TIMP3 underlies diabetic nephropathy via FoxO1/STAT1 interplay. EMBO Mol Med. 2013;5(3):441-55.

50. Guo F, Zhang Y, Wang Q, Ren L, Zhou Y, Ma X, Wu L, Qin G. Effects of FoxO1 on podocyte injury in diabetic rats. Biochem Biophys Res Commun. 2015;466(2):260-6.

51. Arakaki K, Chinen K, Kamiya M, Tanabe Y, Tawata N, Ikehara F, Uehara K, Shimabukuro H, Kinjo T. Evidence for an association between increased oxidative stress and derangement of FOXO1 signaling in tumorigenesis of a cellular angiofibroma with monoallelic 13q14: a case report. Int J Clin Exp Pathol. 2014;7(12):8972-9.

\section{Publisher's Note}

Springer Nature remains neutral with regard to jurisdictional claims in published maps and institutional affiliations.

\section{Ready to submit your research? Choose BMC and benefit from:}

- fast, convenient online submission

- thorough peer review by experienced researchers in your field

- rapid publication on acceptance

- support for research data, including large and complex data types

- gold Open Access which fosters wider collaboration and increased citations

- maximum visibility for your research: over $100 \mathrm{M}$ website views per year

At $\mathrm{BMC}$, research is always in progress.

Learn more biomedcentral.com/submissions 